\title{
Etnografía, mediaciones y pragmatismo
}

\author{
Ethnography, mediations and pragmatism
}

\author{
Ornela Boix \\ Instituto de Investigaciones en Humanidades y Ciencias Sociales, \\ Universidad Nacional de La Plata, Consejo Nacional de Investigaciones Cientificas y Técnicas, \\ Argentina \\ ornelaboix@gmail.com
}

\author{
Pablo Semán \\ Instituto de Altos Estudios Sociales, Universidad Nacional de San Martín, \\ Consejo Nacional de Investigaciones Cientificas y Técnicas, Argentina \\ pabloseman@hotmail.com
}

\section{Resumen:}

Desde un campo de investigación que hasta cierto punto conforma una subdisciplina -la sociología de la música y los aficionados-, la obra de Antoine Hennion contiene un aporte específico y relevante para las ciencias sociales. Los esfuerzos de Hennion cuestionan los límites del construccionismo y dan lugar a una sociología de las irreversibilidades que integra en ensambles heterogéneos las relaciones entre lo humano y lo no humano. En su trabajo, la música ya no será sólo aquello que privilegia la musicología. Pero tampoco esto será negado en nombre de fuerzas sociales abstractas que parecen ser superiores a todas las realidades. La música será una relación, un arreglo heteróclito que debe ser aprehendido en esa complejidad. En este trabajo nos referimos a las discusiones emergentes de su obra que permiten extraer algunas consecuencias para la práctica etnográfica contemporánea. De acuerdo con este objetivo, exponemos primero la posición de Hennion frente al constructivismo, luego abordamos el sentido que cobra el pragmatismo en su elaboración reciente y, finalmente, revisamos los aspectos de la práctica etnográfica que podemos poner en cuestión desde este punto de vista. Específicamente, destacamos el valor del concepto de pragmata para reformular el problema del "punto de vista del nativo" y, sobre todo, para acentuar el carácter dialógico del trabajo etnográfico.

Palabras ClaVe: Etnografía, Música, Constructivismo, Pragmata.

\section{ABstract:}

From a field of research that forms a sub-discipline -the sociology of music and the amateurs-, the work of Antoine Hennion contains a specific and relevant contribution to social sciences. Hennion's efforts question the limits of constructivism to give rise to a sociology of irreversibilities that integrates the relations between the human and the non-human into heterogeneous arrangements. In his work, music will no longer be just what musicology privileges. But this will not be denied in the name of social forces. Music will be a relationship, a heteroclite arrangement that must be apprehended within that complexity. In this paper, we refer to emergent discussions of his work, which offer us the possibility to draw consequences for the contemporary ethnographical practice. With this purpose, we first expose Hennion's position respect to constructivism, then we explore the sense of pragmatism in his recent work and finally we review the aspects of ethnographic practice we call into question from that perspective. Particularly, we underline the value of pragmata as a concept which affords us to rethink "the native's point of view" and, specially, to emphasize the dialogical character of ethnographic knowledge.

KeYWORDS: Ethnography, Music, Constructivism, Pragmata.

\section{INTRODUCCIÓN}

Con un retraso para nada inocente respecto de su tiempo de emergencia en el contexto de su origen francés, el escenario latinoamericano, y especialmente el argentino, comienzan a ser sensibles respecto de los 
planteos teóricos del pragmatismo. Esto ocurre casi al mismo tiempo que se da una situación en que la legitimidad expandida del método etnográfico está de cierta manera asegurada para la investigación en sociología y antropología y goza de algún prestigio incluso entre cientistas políticos, periodistas, administradores gubernamentales.

Resulta interesante realizar una reflexión fundada acerca de las consecuencias que tiene la irrupción de un nuevo arsenal teórico respecto del método etnográfico. Este no puede definirse suficientemente a partir de la idea de sentido común de que es el método que capta la realidad social desde el "punto de vista del actor o del nativo". Semejante definición lleva implícitos al menos dos problemas. En primer lugar, que a pesar de la simpleza técnica que sugiere la definición sabemos que el "punto de vista del nativo" no es ni fácilmente abordable porque no es inmediato ni transparente y porque no es formulable sin graves riesgos de sobre o subinterpretación. En segundo lugar, por algo que es lógicamente anterior: el "punto de vista del nativo" es una noción que depende de una teoría de la sociedad que porta el etnógrafo y es esta la que, por acción u omisión, consciente o inconscientemente da sentido y constituye, inclusive, a lo que se toma como "el punto de vista del nativo" (Semán, 2006; Balbi, 2012). Lo que dice el diario de campo y la experiencia registrada sobre los "nativos" puede ser interpretado de maneras muy diferentes. Más aún: el diario de campo en que sedimenta y leva el registro etnográfico se constituye en la escritura y la propia observación de maneras muy diferentes de acuerdo con la posición teórica del etnógrafo para construir y dimensionar sus objetos, para que ciertas cosas queden o no invisibilizadas a sus ojos, aun cuando ese observador esté dispuesto a que "la realidad" lo desafie y lo supere. ${ }^{2}$ La inmersión en lo real que podría ser concebida como aquello que no le deja al investigador espacio para mantener sus convicciones apriorísticas, es un dispositivo para hacer que la "realidad" supere al investigador. Pero al mismo tiempo la definición de este dispositivo, que se transmite en cada clase, antes de cada práctica, puede transformarse en un anestésico. Entre el uso mecánico de esas nociones y las modas por las que un marco teórico se impone, hecho social verificable en la sistemática variación de las etnografías de acuerdo con la última o anteúltima gran teoría, nos hacen sospechar que ese dispositivo puede perder su capacidad de conmoción.

En este contexto, y aun cuando no tengamos una pretensión de establecer una filiación exclusivamente "pragmática" ni mucho menos un dogma, nos referiremos a los planteos emergentes de las obras de Hennion (2002, 2010, 2017), en tanto tienen el valor de obligarnos a extraer algunas de las consecuencias para la práctica etnográfica "realmente existente". De acuerdo con este objetivo, expondremos primero la posición de Hennion frente al constructivismo, luego abordaremos el sentido que cobra la posición pragmatista en su elaboración contemporánea y, finalmente, revisaremos los aspectos de la práctica etnográfica que resultan puestos en cuestión y relevancia por estas formulaciones. El conjunto del recorrido nos servirá para subrayar las siguientes cuestiones: el valor de una ciencia social que siendo hospitalaria con los "objetos" supere las dicotomias y reducciones implícitas en el concepto de cultura y en la mirada constructivista, el valor del concepto de pragmata para tornar operativa una concepción de "punto de vista del nativo" y, sobre todo, para acentuar el carácter dialógico del trabajo etnográfico.

\section{ACOger a los obJetos, uNA PROPUESTA LLEVADA AL LÍMITE}

El constructivismo no carece de méritos: en tanto consideración teórico-metodológica invita en cada ocasión a reanudar el análisis empírico para mostrar de qué manera la sociedad no se halla ni preconstituida ni teleológicamente orientada, o sea es un resultado del juego histórico y es entonces contingente. Esta orientación ha nacido de un impulso al que radicaliza: uno de los sentidos dominantes de la apuesta histórica de las ciencias sociales, incluso en versiones distantes del planteo alemán del siglo XIX, se sostienen en el supuesto de una oposición entre lo social y lo natural. La necesidad es desde este punto de vista una categoría del reino de lo mineral o lo biológico y en ella reinan lo universal y lo necesario. En oposición, la cultura es el reino de lo arbitrario y lo contingente y tiene un modelo de conocimiento propio. 
Esa es quizás la raíz de algunos límites que enfrenta el constructivismo. Al recibir acríticamente ese planteo constitutivo, aun cuando se exija superar las antinomias de lo subjetivo y lo objetivo, de lo material y lo ideal, de lo particular y lo universal, de lo humano y lo no humano, tiende a olvidar los efectos de las construcciones históricas, que se oponen a la historia como "cosas" (que no por ser fabricadas son evanescentes y reversibles de forma inmediata y voluntarista o por el simple efecto de ser denunciadas como tales). Las transformaciones de largo plazo, las sedimentaciones de camadas de sentido tienen efectivamente una duración y una eficacia que el antiesencialismo en piloto automático no puede aceptar. Pero hay algo que en esta línea es más complejo aún: no se trata simplemente de remontar marcha atrás el camino que ha consolidado determinadas interpretaciones frente a otras que hubieran sido posibles, ni siquiera de reconocer la conjunción de materialidades y representaciones que ha dado lugar a que se cristalicen determinadas subjetividades como sucede en la versión foucaultiana. Se trata de reconocer en esas configuraciones la capacidad de operar como plataforma de otros eventos, de que la no necesidad de su advenimiento no es equivalente a negar su capacidad de determinación a futuro. Y se trata también de reconocer en esas configuraciones y arreglos su carácter necesaria e irremediablemente híbrido (luego especificaremos el sentido de esta afirmación).

La profundización de este desafío es el punto al que nos llevan desde hace un tiempo obras como las de Antoine Hennion o Bruno Latour al plantear la doble necesidad de una sociología capaz de acoger los objetos (aquello que el construccionismo siempre logra tornar líquido en el juego de las resignificaciones constantes) y de asumir que la composición de lo social avanza a puntos de irreversibilidad que las dinámicas construccionistas, por definición, deben ignorar, pues para ellas la naturalización es el demonio.

La obra de Hennion trabaja con las irreversibilidades en el caso de la música, enfrentándose al hecho de que la música en tanto realidad sonora es volátil y ofrece por ello el máximo de resistencia a una sociología que se preocupe de ellas. Irreversibilidades, en tanto condicionamientos a los hechos futuros, consecuencias inevitables, a la vez ancladas en materia que se oponen como objeto a renovar los ciclos de la acción social, formando parte de ella misma. En su análisis de la disputa entre los barrocos y los modernos acerca de la manera adecuada de tocar la música antigua, previa a la constitución de la llamada "música clásica", Hennion muestra una controversia donde los primeros buscan tocar un sonido perdido -es la verdad histórica y musicológica la que debe imponer su ley a los intérpretes actuales (Hennion, 2002, p. 32)- y los segundos tocar lo que está anotado en la partitura, defendiendo la técnica y el gusto modernos para ejecutar la música previa. Revisitar la polémica le permite a Hennion plantear una regla de método fundamental: no hay que decidir entre uno u otro bando, sino restituir sus lógicas, "dejar que levanten sus construcciones musicales y comprender sobre qué fundamentos se apoyan” (Hennion, 2002, p. 53). Así, cada una de estas configuraciones musicales es constituida por una heterogeneidad de elementos que se pliegan, que se apoyan, unos a otros, formando un sistema articulado que define una manera de tocar, una sensibilidad, un gesto, ya sea "clásico" o "barroco".

Frente a lo que un constructivista entendería como dos sistemas de convenciones colectivas en las maneras de tocar y concebir la música, Hennion agrega lo que podría llamarse la "otra mitad" (Hennion, 2002, p. 361) implicada en la construcción de un mundo musical: los dispositivos, los instrumentos, los montajes, en definitiva, los objetos, comprendidos en su apertura, despliegue e inscripción que hacen que una música sea una y no otra. Elementos como "instrumentos, partituras, escenarios, medios de comunicación, intérpretes, profesores, productores, críticos...” (Hennion, 2002, p. 25), son enumerados en distintos trabajos de Hennion para ilustrar de qué hablamos cuando hablamos de mediadores: estos no son abstracciones sino elementos concretos, activos, específicos para cada configuración musical. Esta clase de entramados humanos y no humanos realizan en cada ocasión un trabajo de mediación en la medida en que permiten, invitan, inhiben y/o detienen la constitución de distintos estados de la música. Si bien una lectura rápida de la obra de Hennion puede resaltar la fluidez y la permutación permanente entre estos estados, es preciso ver que cada uno de ellos condiciona el regreso a un estado anterior y modela el estado siguiente. 
La noción de mediación musical refiere a esta clase de entramados de humanos y objetos que producen irreversibilidades. El término no debe confundirse con el de intermediación, dado que no hablamos aquí de una actividad que pone en contacto, desplaza o difunde entidades preexistentes, sino de un trabajo que origina al mismo tiempo al objeto musical y a los sujetos del gusto que esa música exige. En particular, la idea de mediación no remite a los contenidos de ninguna teoría acerca de las mediatizaciones de la industria cultural, en tanto medios de producción, circulación y difusión de las obras musicales. Tampoco el concepto de mediación invoca un mero "rejunte" de elementos sino a una producción permanente, un trabajo concreto, en el que intervienen distintas agencias. Así las cosas, la música es el resultado de estas mediaciones, o más bien, la música es la propia relación de mediación y no tiene existencia por fuera de ella. El concepto de mediación, entonces, no resuelve nada de antemano: es una pregunta que se lanza cada vez a las músicas reales, particulares y concretas: ¿cómo están hechas?, ¿sobre qué arreglos se apoyan?, ¿qué hacen?, ¿qué hacen hacer?

\section{Mediación y traducción: "El que hace lo más hace lo menos"}

En esa interrogación que define el corazón de la noción de mediación reside una apuesta por superar el dualismo: entre el sujeto y el objeto, entre la obra y la sociedad, entre lo humano y lo no humano, oposiciones que se sintetizan de acuerdo con Hennion en dos aproximaciones analíticas polares e igualmente reduccionistas del fenómeno musical: el esteticismo y el sociologismo. En un extremo, las lecturas estéticas de la música aceptan y comentan el objeto musical, al que consideran en tanto que obra autónoma, de la cual derivan los términos de la apreciación estética. Delimitan así los contornos de una "pareja trascendente" entre el objeto y el sujeto del gusto musical. En el otro polo, y en el intento de desligarse de la ponderación normativa de los esteticismos, como también del estatuto de excepción que otorgan al objeto y a la experiencia artística, las lecturas sociológicas disuelven la música en un juego social, ya sea de diferenciación o distinción entre los grupos, de lucha de clases o de identidad, prescindiendo de las características específicas del objeto musical, que se convierte en un mero signo arbitrario, y de los usos en los que se ve implicado. De esta manera, mientras en los esteticismos todo remite a la obra, en los sociologismos todo señala a la sociedad. En una propuesta de superación de estos dos polos de interpretación sobre la relación entre música y sociedad, Hennion recupera para el análisis las mediaciones, los "mixtos" de cosas y humanidad, conduciéndonos a un "repoblamiento del mundo musical” (Hennion, 2002, p. 19) en el que obra y sociedad, sujeto y objeto, se coproducen. La sociología de la mediación, en definitiva, implica:

tomar en serio la inscripción de nuestras relaciones en las cosas, y no en deshacer con el pensamiento, como si no resistieran, los montajes y dispositivos a la vez físicos y sociales que sirven para establecer semejante reparto, situando de un lado un objeto autónomo y del otro un público sociologizable. Interpretar no es explicar, regresar a la pureza de las causas únicas, exteriores, que los actores buscan tanto como nosotros, sino mostrar las irreversibilidades que, por todas partes, han interpuesto los mixtos, entre los humanos, entre las cosas, entre los humanos y las cosas: ¿qué otra cosa es la música? (Hennion, 2002, p. 363).

Es casi redundante en este contexto hablar de "música y sociedad". No solo porque la música antes que expresar a la sociedad resulta constitutiva de ella como de distintas formas se plantea esa tesis desde Adorno hasta Tia DeNora sino también porque desde esta perspectiva la música es una sociedad ella misma.

El concepto de mediación y la idea de irreversibilidad pueden dilucidarse mejor en su contenido y alcance en diálogo con las consideraciones de Latour con las que la obra de Hennion guarda una relación de retroalimentación. Como plantea el propio Hennion, el concepto de mediación puede ser aplicado tanto a la música como a los proyectos técnicos (en efecto el concepto es usado por Latour -2012- para explicar el trabajo de purificación en la constitución moderna de las ciencias y de la propia modernidad: purificar implica un esfuerzo de separación absoluta entre lo humano y lo no humano de lo que es, desde un inicio, híbrido). Pero para dar cuenta de la heterogeneidad y apertura de los objetos de la ciencia, Latour y Callon acuñaron por la misma época el concepto de traducción, noción adecuada a las especificidades de un objeto 
considerado cerrado e intocable por el consenso sociológico. Traducción, en tanto el proceso en el que convergen múltiples intereses que no sólo son transportados por humanos sino por objetos en el ensamblado de una red, que produce efectos en las relaciones y los cursos de acción (proceso que Latour abstrae de la lógica con que funciona la ciencia realmente existente, no la exaltada por el falsacionismo de gabinete ni la destituida por la epistemología crítica). Para el caso de la música, por el contrario, había que demostrar la resistencia de un objeto considerado evanescente, al punto de que todo en ella era "socialmente construido". Dicho groseramente: una "sociología hospitalaria con los objetos", como la llama Hennion, es más difícil en el campo de la sociología de la cultura que aparece reducida a signos, a espíritu, a "vapor" (por efecto de la purificación que Latour denuncia), que en el campo de la sociología de la ciencia en el que los razonamientos parecen más vinculados a la "materia". Este argumento, que es ilustrativo y es sólo aceptable desde el punto de vista de la constitución moderna que Latour explica en sus fracasos (ya que cualquier historia del arte revela de inmediato hasta dónde, y en un sentido muy diferente al que afirmaban Marx y Engels, el sentido nace "tarado por la materia"), puede servirnos para precisar el valor heurístico de la noción de mediación.

Para el caso de la música, mediación era una noción más apropiada al referir no sólo a los pasajes y asociaciones entre lo humano y lo no humano presentes en la idea de traducción, sino a la manera en que estas asociaciones habilitan o inhiben el juego social. Como lo expresa Hennion (2017, p. 5):

el mismo proyecto que, en el caso de la ciencia, consistía en hacer más social lo que era visto como objetivo, buscaba, al contrario, en el caso de la cultura, respetar la objetividad de lo que la sociología reducía a signos sociales, a marcas de diferenciación entre los grupos.

Es así como los conceptos de traducción y mediación se plantearon tareas diferentes y opuestas en un mismo programa de investigación. Cabe señalar que, al mostrar la producción de irreversibilidades para el caso de la música, el concepto de mediación asumía un desafío mayor que el que tomaba el de traducción en cuanto a la disputa con el sociologismo. De esta manera, podría pensarse que el concepto de mediación cumple más abarcativamente que el de traducción el programa global de dar cuenta de la agencia de los objetos que reúne a los dos autores.

La demostración de que en el ámbito "espiritual" de la "cultura" las "cosas" operan obliga a responsabilizarse por dos consecuencias encadenadas. La primera: si esto es así con la "cultura” hasta qué punto no es mucho más necesario tomar en cuenta esa actancia cuando se trata de ámbitos que no son el reino del puro símbolo. La segunda es más radical aún: el hecho de que la cultura ya no pueda ser concebida de forma tan desencarnada (y no sólo por efecto de la crítica marxista), ¿ no obliga a cuestionar nuestras divisiones entre la "cultura" y las "cosas"?

\section{Pragmatizar es COMPlejizar}

La apertura al pragmatismo más recientemente desarrollada por Hennion profundiza, da nueva consistencia y un nuevo lenguaje a las adquisiciones consolidadas por la vía que venimos describiendo en La Pasión Musical. La apuesta por una forma de totalización que no implica ni cierre, ni unicidad, ni necesidad y el énfasis en la relación le dan positividad ontológica al movimiento que, al mismo tiempo, superaba el construccionismo y volvía a la sociología "hospitalaria con los objetos”. Esa apuesta y ese énfasis y su resultado pueden entenderse en un recorrido que comienza por "algo" que es al mismo tiempo básico y compuesto o complejo.

Ese "algo" es una consecuencia de que ni el sujeto es el centro del mundo ni las "cosas" están definitivamente hechas si no que ofrecen asideros - "affordances"- (en el lenguaje de Tía DeNora -2000-) a los usos que esas mismas "cosas" sugieren y acaban aceptando en arreglos en que cosas y humanos participan. En la elaboración de DeNora (2000), una pelota, por ejemplo, no engendra las mismas prácticas lúdicas, ni se remite a la exclusiva posibilidad de habilitar juegos: puede ser adorno, mueble, objeto terapéutico. Sin embargo, en la 
versión de DeNora los objetos son considerados en sus usos, pero no se encuentran aún en el centro del análisis como en los trabajos de Hennion (2010) sobre los aficionados. Estas últimas investigaciones producen un salto cualitativo por sobre el concepto de habilitación, en tanto ellas no permiten entender a los aficionados fuera de una red de vínculos con sus objetos. Así, mientras en la aproximación de DeNora sujeto y objeto son parte de una suma, en la concepción de Hennion sujeto y objeto se metabolizan en una síntesis. Recordemos el caso de uno de los aficionados con que trabaja Hennion, Philippe, un médico que compra muchos discos y los escucha en una sala especial a la que tienen prohibido entrar sus hijos, su esposa y el perro. Ante la cantidad de discos comprados, comienza a amontonar las novedades y sus predilectos en un extremo de la biblioteca y dejando en el otro extremo los discos que no le despiertan tanto interés. Con el tiempo se da cuenta que este sistema es mejor que la clasificación por géneros o por estilos. Se ha construido, sostiene Hennion, un dispositivo, una prótesis de escucha, donde los objetos acompañan y ordenan su gusto.

Este régimen de determinación/indeterminación múltiple entre los objetos y los sujetos no puede concebirse con categorías como acción u objeto sino justamente a partir de las vinculaciones en que ellos existen en situaciones históricamente plurales y contingentes. Esas vinculaciones constituyen algo así como sus estructuras elementales. Es allí donde una lectura del pragmatismo ofrece una solución si no confundimos pragmatismo con ideología utilitarista, la papelera de reciclaje a la que casi siempre se arroja la filosofía de James, Dewey y Peirce, entre otros. Tomado como una ontología, y no como un método, como una forma de referir al ser de lo existente y no como una forma de acceder a las cosas, el pragmatismo entiende que las cosas son las relaciones en que existen sujetos y cosas siempre en usos y arreglos que terminan de definirlas. Esas asociaciones son las pragmatas en las que se integran indisolublemente aquello que el dualismo divide y opone como sujeto y objeto absolutos, vinculaciones sin las cuales no hay sujeto u objeto.

Las pragmata existen como tales, como asociaciones en las que la agencia está distribuida en la asociación misma entre el sujeto y el mundo y no exclusivamente en el sujeto. Existen como posibilidad afirmada en un campo de posibilidades del que emergen como alternativa, superación, desvío, deriva, actualización no única y que define a ese campo como un pluriverso, una totalidad no cerrada y no sellada a la que referir las pragmata. En este sentido la pragmata abraza un conjunto de complejidades: relaciones (primera complejidad) que solo pueden existir como parte de un conjunto de posibilidades de relación (segunda complejidad) que nos permiten entender, contra el sentido común, que el pragmatismo de esta concepción tiene poco de práctico si por esto se entiende simplificar, resolver e instrumentar.

Es en ese contexto que el análisis sociológico acompaña a las pragmata haciendo que emerjan como tales. Lo que obliga a un movimiento aparentemente contradictorio que redefine la noción de crítica a la cual se asocia la misión de la sociología. Cuando el análisis procede haciendo aparecer el mundo así lo que hace es aceptarlo en su pluralidad, su apertura, la incertidumbre radical de los seres que surgen de él, sin nunca parar de cuestionar nuestras maneras de pensar. No hay necesidad de distancias críticas desde afuera, el mundo es el mismo plural, abierto, en crisis permanente (Hennion, 2017, p. 13).

La tensión entre la aceptación y la crítica revela su carácter de contradicción puramente aparente porque estos dos términos pierden su carácter opuesto cuando se considera la pluralidad del mundo y que la emergencia de un posible entre otros es al mismo tiempo aceptación de esa posibilidad y superación de cualquier noción de necesidad. Así, y al mismo tiempo, esto tiene una consecuencia específica para entender la posibilidad crítica que entraña el pragmatismo al que acude para especificarse una teoría de las mediaciones. Esta teoría que nace de la crítica al proyecto crítico, en tanto este instaura un punto de vista falso y artificiosamente exterior para realizarse como tal, retorna a una de las propiedades que definían al proyecto crítico: este debe ser una crítica inmanente. Pues bien: despojado de la geometría que la dialéctica imponía al razonamiento de Adorno, y vuelto humilde por superación del filósofo héroe a favor del hombre común la tarea de aceptación del pragmatismo, que no puede ser sino crítica, porque cuestiona la fatalidad y la necesidad, se despliega desde el lugar mismo en que el mundo sucede, múltiple, o sea como inmanente. 
Yace aquí subentendida la devolución de la facultad crítica al "hombre común" que había emprendido Michel de Certeau (2000) una influencia que pulsa como un bajo en la obra de Hennion. Y esto motiva la necesidad de sacar consecuencias metodológicas específicas del pragmatismo ontológico que da nuevo vigor a la idea de mediación.

La referencia que hacemos a De Certeau no es casual ni para nosotros ni para Hennion. Ella además de desempeñar un papel clave en La pasión musical ${ }^{3}$ ayuda a iluminar algo que es necesario explicitar en el valor de la noción de pragmata que estamos analizando. Para comprender cabalmente esa referencia y lo que está en juego en ella debemos retornar a una problemática en la que esa referencia se inscribe, porque es ella en su conjunto la que nos permite calibrar mejor la noción de pragmata y de crítica que está en juego en la percepción que alienta Hennion. Esa problemática es para nosotros la que presenta Foucault y la posición de Hennion puede leerse respecto de esa presentación como una tentativa de superación crítica que está mediada, justamente por la posición de De Certeau.

Sabemos que la obra de Foucault continúa de forma actualizada algunas de las ideas clásicas de la escuela de Frankfurt en lo referente a la determinación de la subjetividad por lo social y a la actividad crítica que permite posicionarse frente a esa determinación. Foucault percibe a niveles micro y macro la amplitud y la intensidad de esa determinación y al mismo tiempo trasciende el imaginario racionalista que, pese a todo, se mantiene en la versión pesimista de Adorno. La noción de dispositivo (Foucault, 1984) contiene esa cuestión: el arreglo de elementos heterogéneos en que consiste un dispositivo (desde reglas hasta una determinada arquitectura) y que, justamente, dispone la acción en un determinado sentido, guarda una relación de semejanza y diferencia estratégica con la noción de pragmata que venimos comentando.

La hospitalidad con los objetos que permite constituir esa noción ya estaba presente en la elaboración de Foucault en la idea de dispositivo. En los dos casos se trata de composiciones entre lo "humano" y lo "no humano", entre lo material y lo simbólico. Y en las dos nociones hay una refinada atención al hecho de que los vínculos entre esas dos series de elementos tienen múltiples posibilidades y no dan lugar a relaciones necesarias. La relación que se da entre objetos, prácticas, significación solo adquiere carácter de necesidad una vez que alrededor de esa relación contingente se suman relaciones, factores históricos, que hacen que esa posibilidad contingente gane condición "estructural". Pero incluso esa necesidad es relativa, pues la multiplicidad de las posibilidades de vinculación hace que los dispositivos y las pragmatas sean inestables y tengan posibilidades de desplazamiento que hasta cierto punto son tan inevitables como imprevisibles.

¿Entonces la noción de pragmata es igual a la de dispositivo? No, y justamente en ese punto podemos retomar la relación entre De Certeau y Hennion. La posición del primero frente a Foucault permite entender la diferencia entre esos dos conceptos más allá de sus intersecciones. De Certeau estructuró su obra siguiendo un régimen de anti afinidades electivas, es decir de debates privilegiados con autores cuya posición vale la pena incorporar y al mismo tiempo superar y discutir. En ese contexto la posición de Foucault le resultaba tan acertada como parcial: se trataba de aceptar en la amplitud y la sutileza de las determinaciones que se imponen al sujeto y lo producen como tal, pero de entender también de las múltiples posibilidades de insubordinación que se despliegan justamente a través de la malla que instituye al sujeto, que impone y dispone la acción. Allí donde Foucault observaba las exclusiones, De Certeau reparaba en los "excluidos". Podrá decirse que los triunfos de los débiles que De Certeau expone como realidad y posibilidad resultante de ese resto de subjetividad no reificada son triunfos temporales y tácticos cuyo valor podemos discutir en otra oportunidad, pero no puede negarse que conceptualmente se trata de discernir posibilidades de subversiones que son "ontológicamente" tan probables como la dominación que se padece. De esa posibilidad que para De Certeau está democráticamente distribuida porque es "universal” dada la relación del sujeto con el lenguaje, el incosciente y la propia realidad de la materia, nace el hecho de que la crítica inmanente que Adorno o Foucault reclaman no tenga un sujeto privilegiado (el "docto") sino que resida en las facultades del hombre común. La crítica del proyecto crítico que está en las raíces del proyecto del intelectual del que participa Hennion tiene en esa condición teorizada por De Certeau en debate con Foucault su condición de posibilidad. Hacer 
aparecer las pragmatas es justamente concretar esa posibilidad crítica (de lo real y del proyecto crítico) en su diseminación real, contra el a priori de que esta posibilidad solo podría ser actualizada por un héroe necesariamente extraño y solitario como el filósofo y el artista de vanguardia.

Pero no es la única diferencia: de lo anterior se deduce que mientras en la noción de dispositivo no hay lugar para una agente que siempre es una derivación, en la crítica de De Certeau, y en la noción de pragmata, hay siempre un resto de subjetividad capaz de obrar y trascender a las capturas y las dispositivaciones en que esa subjetividad emerge.

Según el propio Hennion (2017), en el diálogo entre distintas ramas de la sociología francesa y la importación de las teorías de la acción norteamericanas, se dibujan a partir de los años ochenta tres movimientos que anteceden al suyo propio. En primer lugar, la sociología de las ciencias y las técnicas, identificada a veces como STS (Science \& Technology Studies), e impulsada principalmente por trabajos de Latour y Callon, proponía el tratamiento simétrico entre los objetos y los sujetos, los humanos y las cosas. En segundo lugar, dentro de este giro pragmático también se contaban investigaciones como las de Luc Boltanski, Michael Pollak y Laurent Thévenot, interesados en la elaboración de modelos de acción sensibles, apoyados en los objetos, aunque sin abandonar los marcos de una teoría de la acción. Por último, los trabajos nucleados en el CEMS (Centro de estudio de los movimientos sociales), central en la lectura francesa de la etnometodología y en la renovación de las perspectivas de investigación sociológica sobre la pragmática de la acción colectiva.

\section{OTRO SENTIDO PARA LA EXPRESIÓN ETNOGRAFÍA}

El trabajo de Hennion no parte del método etnográfico, ni lo teoriza como recurso privilegiado, pero tiene al menos dos tipos de relaciones que iluminan cuestiones de su práctica. Una que hace la comprensión totalizante de la investigación y otra que se relaciona con el carácter dialógico del método etnográfico. Desde nuestra perspectiva no es tan importante enunciar la mejor versión posible del método (cosa que además hallamos imposible) sino subrayar el sentido en que las formulaciones de Hennion nos ayudan a discutir lo que surge en algunas versiones de este, vistas las prácticas de los etnógrafos.

\section{Totalidad y mediaciones.}

Partamos de algo que ya hemos señalado: la música no es algo inmediatamente dado sino un conjunto de mediaciones que es preciso hacer aparecer en un trabajo que se remonta hacia todo lo que pulsa en lo que nos aparece como música. En este caso es preciso entender que la ontología de los objetos propuesta por Hennion implica una idea de totalidad singular, multidimensional y en movimiento que implica al mismo tiempo el trabajo artesanal y multisituado del investigador que remite sino a todas a algunas de las formulaciones clásicas del método etnográfico, como, por ejemplo, la de Marcel Mauss: el hecho social en su multidimensionalidad tanto en los aspectos significativos como en su materialidad. Pero en el caso de Hennion la referencia a la totalidad puede reconocerse más explícitamente en el diálogo con Becker que especifica el sentido de la totalización y su relación con el método etnográfico y con una teoría de las mediaciones.

Becker en su intención de relativizar las mistificaciones del arte o del comportamiento desviante, propone cambiar las preguntas y con ello propone una vía metodológica. Al considerar el caso de los usuarios de marihuana Becker deja de preguntarse ¿por qué se da un cierto comportamiento?, como si hubiera una condición extraordinaria de los sujetos que lo facilitara, y comienza a interrogar las condiciones bajo las que cualquier persona podría transformarse en un usuario de marihuana. Cuando las preguntas se desplazan del ¿por qué? al ¿cómo? la investigación se obliga a dar cuenta de un conjunto de condiciones de la interacción (¿quiénes?, ¿cuándo?, ¿con qué compañías?, ¿con qué herramientas?, ¿con qué aprendizajes?). Como afirma 
Becker (2011, p. 87), aun reconociendo que se trata de una hipérbole, "quería conocer todas las circunstancias alrededor de un acontecimiento", "Quería conocer las secuencias de las cosas, cómo una cosa llevaba a la otra” o sea "mucho más de lo que acostumbran a querer los científicos sociales". Por ello se exige a sí mismo intentar entender las cosas en un espacio afirmando que "todo tiene que estar en un lugar" y reclamando al mismo tiempo "poner dentro todo lo que no puede quedar afuera", es decir darle el carácter de parte de los hechos a los elementos que irresponsablemente llamamos "contexto" como si los fenómenos sociales se dividieran entre una secuencia causal aislable y un espacio donde se empotran. Así su concepción de las exigencias de la investigación empuja el esfuerzo del investigador a la descripción de un proceso complejo en su singularidad que implica como mínimo un compromiso con el método etnográfico en tanto "descripción verbal detallada" (Becker 2015, p. 27).

No se trata de una mera "contextualización": Contexto es también una noción para dudar en el marco de una consideración pragmática: el sujeto enredado y definido como tal en mediaciones y pragmatas no tiene al contexto como una plataforma fija que le da sede a la acción sino como una mochila que contiene los recursos que el sujeto moviliza y se redefine por estas mismas acciones. En esa perspectiva la diferencia entre texto y contexto se vuelve casi irrelevante.

La concepción de Hennion conserva en su infraestructura teórica esta noción que hasta cierto punto solicita al método etnográfico al mismo tiempo que le propone un marco interpretativo que permite construir el campo más acá de las distinciones entre sociedad, cultura y naturaleza o entre individuo y sociedad. Desde este punto de vista corresponde al etnógrafo abrir, desplegar y recorrer ese campo de mediaciones. No sabemos hasta donde la etnografía es la única vía para una teoría de las mediaciones, pero sabemos que es pertinente y que esta redefine el arsenal de instrumentos interpretativos del etnógrafo.

\section{Conversación}

Este compromiso entre teoría de las mediaciones y método etnográfico obliga a considerar la especificidad de una cuestión: ¿cuál es el papel del sujeto en una teoría de las mediaciones? ¿Cuál es la posición del etnógrafo frente a ese sujeto?

Algunos etnógrafos, sobre todo algunos profesores de método etnográfico, acostumbran a decirnos, en un discurso escolarmente escandido, que el enfoque etnográfico, que no es ni el método ni el texto (que también son parte del método), implica una atención, un respeto por el punto de vista del nativo. Resta el pequeño problema de cuál es la teoría que permite identificar, interpretar y situar el "punto de vista del nativo" que de ninguna manera es evidente.

La penumbra en la que permanece esa cuestión es el motivo por el cual la gran popularidad de la que goza actualmente el método etnográfico no necesariamente es acompañada de una conciencia crítica acerca de lo problemática que resulta esta definición y de lo contradictorias que resultan con ella algunas de sus versiones: por ejemplo aquellas que acuden al punto de vista nativo para luego interpretarlo por una condición totalmente exterior al campo de interlocución en que se constituye una etnografía (es como resolver un juicio acudiendo a la jurisprudencia antes que al análisis de la singularidad del caso). Ha sido muy fácil en estos años leer etnografías en las que las artes interpretativas del sociólogo se basan antes que nada en saber aquello que el actor no sabe, en la posibilidad de inscribir el discurso nativo como portador de un sentido semipleno y contradictorio cuyo establecimiento y equilibrio definitivo depende del intérprete que propone un contexto no advertido por el sujeto para devolverle así alguna conciencia. Es preciso recordar aquí esas versiones y contradicciones por el punto de contraste que ofrecen al cruce fructífero que se da entre el método etnográfico y la intervención de Hennion con elementos presentes en este mismo. Esta intervención tiene un doble valor: si por un lado antepone una teoría de la totalidad que rompe la ilusión de ingenuidad acerca de la transparencia del punto de vista nativo, por otro propone un papel específico, productivo y cognitivamente iluminador para el sujeto que habita esa totalidad y con el cual el etnógrafo dialoga. 
De una forma que especifica la consideración pragmática, Hennion ha enfocado la investigación de los aficionados a diversas prácticas incluida la escucha musical. Ese conjunto de trabajos ayuda tanto a situar el problema que señalamos más arriba en la práctica del enfoque etnográfico y sus consecuencias en el plano metodológico, como a señalar una vía de superación a partir de la consideración del lugar decisivo que desempeñan operadores clave como lo son en el caso de la música o el consumo de vino, los "aficionados". No se puede seguir viendo en los aficionados la placa sensible que da cuenta de la exposición a los "rayos x" de la obra, las fuerzas ciegas del mercado y las inercias mudas de la estructura social condensadas en cada acto, sino un punto de anudamiento de una propensión que el aficionado cuestiona antes que nadie. Es necesario entender que en la actividad del aficionado no se despliega un "gusto" como actualización (simple o compleja) de una condición previa producto de las determinaciones de una habitualidad que se confronta a un estímulo, sino que es una actividad intensa, cooperativa, siempre en algún grado reflexiva, materialmente interpelada. En ella se establece una vinculación, que es distinta de la expresión de una disposición previa en un conjunto de opciones que cumplen el papel del sucedáneo de la práctica. En una vinculación, el "gustador" trabaja para que el objeto lo llame y se haga amar por él en una situación de incertidumbres y cuestionamientos (nos volvemos fans, no nos revelamos tales y aunque creamos que el objeto nos "llama" como Dios a Pablo de Tarso, subyace a nuestra conversión descripta performáticamente como "repentina" un trabajo de engarzarse con las múltiples posibilidades del objeto y sus habilitaciones). La noción de "gusto adquirido", frecuente en el sentido común y que se usa para designar gustos difíciles, pero socialmente "obligados", como por ejemplo el mate o el alcohol, se pone en la pista de lo que la noción de vinculaciones pone en juego. Esta "rompe la oposición que acentúa el dualismo de la palabra gusto, entre una serie de causas que vendrían del exterior y el «hic et nunc» de la situación y de la interacción"(Hennion, 2010, p. 26) y designa una tarea que no debe ser concebida como el efecto de declaraciones y etiquetas sino como algo que se relaciona con la actividad de las personas y con la capacidad de los objetos de "coproducir lo que pasa" creando un lazo específico.

Sí lo que se llama "sociología espontánea" de los actores es en realidad algo que surge de intentar desconocer que el aficionado, mucho antes que el sociólogo, pone en cuestión la determinación de sus gustos cuestionándolos por la "naturalidad" con que se imponen en su menú, por su carácter de moda, por la evidencia de la frontalidad con que el gusto es solicitado desde la oferta (como lo constata Hennion -2010-, los nativos también son suspicaces como Bourdieu). En vez de una semi conciencia debe verse en el aficionado un crítico en acto, el protagonista de un esfuerzo para hacer que un objeto se haga querer por ese sujeto que en ese movimiento prefigura el esfuerzo del sociólogo (del sociólogo pragmático, claro). Imaginando una sociología soñada y partiendo del papel clave que cumplen los aficionados, Hennion (2010, p. 33) pregunta:

¿Y si, al contrario, escuchando a los aficionados, la sociología reconociera por fin este imperio, mejor dicho, el arte de una relación más intensa y reflexiva que, a través del gusto, los humanos establecen poco a poco con los objetos, con los demás, con su cuerpo y con ellos mismos?

Antes que repudiarlo, corregirlo o ponerlo en su lugar la sociología debe acompañar al aficionado todo el tiempo para dar cuenta de que con él aparece la pragmata. Esta surge en el campo etnográfico en tanto este es el campo de experiencia en que los esfuerzos, vaivenes y soluciones (en el sentido químico de la expresión) surgen en su verdad siempre particular. En ese sentido el aficionado es "profesor de pragmatismo" (Hennion 2017, p. 13): en acto es parte del proceso de asimilación y acomodación con el ambiente y como es reflexivo expone ese proceso en sus impasses, aceleraciones y en las categorías con que este se despliega.

\section{Conclusión}

En este trabajo hemos considerado las consecuencias que la renovación teórica propuesta en las ciencias sociales por autores como Hennion, y su énfasis en la actancia, la agency, de las cosas, tiene 
para la conceptualización y la práctica concreta del método etnográfico, en un momento en el cual las investigaciones que se identifican con este abordaje se multiplican y ganan legitimidad en nuestro medio académico.

Para ello, primero expusimos los límites del constructivismo en tanto apuesta intelectual. Argumentamos que el constructivismo, en su continuidad con el planteo fundador de las ciencias humanas y su división tajante entre el espíritu y la naturaleza, enfatiza en el carácter "socialmente construido" y evanescente de la realidad, por lo que tiende a relegar los efectos de las construcciones históricas. En los planteos pragmatistas estas aparecen recuperadas y sedimentadas como irreversibilidades, como cosas, como objetos que ejercen tanto una resistencia como un apoyo a las acciones futuras. De esta forma, estos desarrollos asumen la contingencia en la producción de configuraciones sociales, sin negar su poder de determinación futura. A esta idea apuntan los conceptos de mediación (Hennion) y de traducción (Latour), cuya comparación revela un proyecto científico en buena medida compartido, uno en el cual hay que "hacer hablar a los objetos" (Latour, 2008, p. 117) o asumir que estos tienen "derecho a réplica" (Hennion, 2010, p. 26). Específicamente, consideramos que la noción de mediación da cuenta más completamente de este programa, al lidiar con un ámbito como el de la cultura, considerado aún hoy como un espacio meramente simbólico.

En un segundo momento, trabajamos sobre la pragmatización posterior de la sociología de las mediaciones. En este corrimiento, esta sociología encuentra una ontología acerca de un mundo que está todo el tiempo haciéndose. Al postular estar muy cerca de los objetos, el pragmatismo es decisivo para Hennion: los objetos no están dados, sino que arriban, se despliegan, cambian de estado, acompañan a los sujetos y son usados por ellos. A esta altura, categorías objeto y sujeto resultan poco operativas y Hennion propone ir hacia las vinculaciones que existen entre ellos de forma plural y contingente, hacia la idea de que al tiempo que hacemos las cosas, las cosas nos hacen a nosotros. Por nuestra parte, precisamos este argumento, referido en los últimos trabajos de Hennion con el concepto de pragmata, en una comparación con la noción de dispositivo presente en la obra de Foucault, lo cual obligó asimismo a pasar por el postulado de la capacidad crítica de los sujetos que Hennion retiene del proyecto de De Certeau.

Por último, y aun cuando la propuesta de Hennion no sea exclusivamente etnográfica, defendimos que viene al encuentro del método etnográfico. Tanto al de la definición limitada que dimos antes "descripción basada en el punto de vista del nativo", como al de una más exigente que pide al etnógrafo que se abstenga de interpretaciones que impliquen un sentido ajeno al campo histórico en que se produce la acción (y esto no implica que el mencionado campo sea exclusivamente el campo de la interacción cara a cara como lo suponen aquellos que reducen la etnografía a microsociología). A estas dos definiciones la propuesta de Hennion viene a ofrecerles una posibilidad. A la primera definición le ofrece una posición menos ingenua y menos empirista acerca de lo que sean el "nativo" y su punto de vista: es preciso hacer aparecer el objeto a través de la red de mediaciones para que el nativo, al que se supone dado se presente. El "nativo" supone una teoría de la totalidad y de las mediaciones en la que su "punto de vista" no es transparente (porque depende de un "contexto", de un juego de lenguaje específico en el que sus palabras tienen una significación particular más allá del diccionario genérico de su lengua -cualquiera sea ella-). Y por esto mismo la aproximación etnográfica no necesariamente es a lo inmediatamente dado, al "cara a cara" al que se reduce la etnografía en tanto método asociado a la exploración de sociedades que con muy mal criterio solía llamarse "simples" y "primitivas".

No deja de tener significado para nosotros el hecho de que Hennion elige resaltar a los historiadores sociales como practicantes de una forma adecuada de abordar los objetos. Aquí cabe un razonamiento transitivo que valida nuestra suposición acerca de las repercusiones que tiene esa postura para entender el método etnográfico en la perspectiva de Hennion. Evans Pritchard al comparar la posición de la antropología social y la historia social discernía un isomorfismo en estas ciencias humanas de una totalidad social en su integridad. Y recordemos que Evans Pritchard estudió sociedades tribales en las que reconoció formas de articulación política de gran escala que daban cuenta de su complejidad sin ceder al prejuicio de que la ausencia de Estado en ellas significase simplicidad. Esto, que se vincula al hecho de que la antropología social inglesa de la que es parte no era ni una microsociología ni una indagación de la cultura separada de lo social sino más bien 
una sociología de ultramar, tiene una particularidad en el caso del autor de Los Nuer: se apoyaba en una concepción del método etnográfico en la que subrayaba, a pesar de sus evidentes y criticados compromisos coloniales, la necesidad y el carácter crucial del elemento dialógico que caracteriza al método etnográfico en algunas de sus versiones contemporáneas.

Si no es con todas las razones no es por nada que en la propuesta de Hennion reside para nosotros un señalamiento de pertinencia indiscutible: si en la antropología como historia social se subraya el elemento dialógico, en la sociología de Hennion, en consonancia se halla inscripta la necesidad de no soltar nunca la mano del aficionado para entender las prácticas.

\section{REFERENCIAS BIBLIOGRÁFICAS}

Balbi, F. A. (2012). La integración dinámica de las perspectivas nativas en la investigación etnográfica. Intersecciones en Antropología, 13(2), 485-500.

Becker, H. (2011). Trucos del oficio: cómo conducir su investigación en ciencias sociales. Buenos Aires: Siglo XXI.

Becker, H. (2015). Para hablar de la sociedad. La sociología no basta. Buenos Aires: Siglo XXI.

Borges, A. (2011). Mujeres y sus casas: retrospectiva y perspectiva de un sendero en antropología y sociología. Revista Estudios Sociológicos del Colegio de México, 29(87), 981-1000.

De Certeau, M. (2000). La invención de lo cotidiano. 1. Artes de hacer. México DF: Universidad Iberoamericana.

De Nora, T. (2000). Music in everyday life. New York: Cambridge University Press.

Ferraudi Curto, M. C. (2014). Ni punteros ni piqueteros. Urbanización y política en una villa del conurbano. Buenos Aires: Editorial Gorla.

Foucault, M. (1984). El juego de Michel Foucault. En Saber y verdad (pp. 127-162). Madrid: Ediciones de la Piqueta. Hennion, A. (2002). La pasión musical. Barcelona: Paidós.

Hennion, A. (2010). Gustos musicales: de una sociología de la mediación a una pragmática del gusto. Comunicar, 17(34), 25-33.

Hennion, A. (2017). De una sociología de la mediación a una pragmática de las vinculaciones. Retrospectiva de un recorrido sociológico dentro del CSI. Cuestiones de sociología, 16, 1-23.

Latour, B. (2012). Nunca fuimos modernos. Ensayo de antropología simétrica. Buenos Aires: Siglo XXI Editores.

Latour, B. (2008). Reensamblar lo social: una introducción a la teoría del actor-red. Buenos Aires: Manantial.

Merenson, S. (2016). Los peludos. Cultura, politica y nación en los márgenes del Uruguay. Buenos Aires: Gorla.

Semán, P. (2006). Ni demonios ni desiertos. En Exploraciones descentradassobre culturapopulary masiva (pp. 175-187). Buenos Aires: Gorla.

\section{Notas}

1 Este artículo reelabora y expande una reflexión previa de ambos autores publicada en Cuestiones de Sociología n. 16, con motivo de la presentación de una traducción del más reciente trabajo de A. Hennion sobre su desplazamiento de las mediaciones a las vinculaciones.

2 Excede a nuestras posibilidades de tratamiento en este espacio la cuestión a la que remite la expresión nativo que congela en el lenguaje una perspectiva colonial de la investigación antropológica y que encuentra soluciones alternativas en trabajos como los de Borges (2011), Ferraudi Curto (2014) o Merenson (2016).

3 Las citas a De Certeau en La Pasión Musical no son profusas, pero resultan estratégicas: ellas aparecen en esta obra como las inspiradoras y al mismo tiempo como horizonte de cierre de la concepción de la mediación como un movimiento generalizado dinamizado por una falta respecto de la cual trabaja, asintóticamente, la representación. 